\title{
Evaluation of a polynya flux model by means of thermal infrared satellite estimates
}

\author{
Thomas KRUMPEN, ${ }^{1}$ Sascha WILLMES, ${ }^{2}$ Miguel Angel MORALES MAQUEDA, ${ }^{3}$ \\ Christian HAAS, ${ }^{4}$ Jens A. HÖLEMANN, ${ }^{5}$ Rüdiger GERDES, ${ }^{1}$ David SCHRÖDER ${ }^{2}$ \\ ${ }^{1}$ Department of Sea Ice Physics, Alfred Wegener Institute for Polar and Marine Research, Bussestrasse 24, \\ D-27570 Bremerhaven, Germany \\ E-mail: tkrumpen@awi.de \\ ${ }^{2}$ Department of Environmental Meteorology, University of Trier, Behringstrasse 21, D-54286 Trier, Germany \\ ${ }^{3}$ National Oceanography Centre, Joseph Proudman Building, 6 Brownlow Street, Liverpool L3 5DA, UK \\ ${ }^{4}$ Department of Earth \& Atmospheric Sciences, University of Alberta, Edmonton, Alberta T6G 2E3, Canada \\ ${ }^{5}$ Department of Observational Oceanography, Alfred Wegener Institute for Polar and Marine Research, Am Handelshafen 12,
}

D-27570 Bremerhaven, Germany

\begin{abstract}
We test the ability of a two-dimensional flux model to simulate polynya events with narrow open-water zones by comparing model results to ice-thickness and ice-production estimates derived from thermal infrared Moderate Resolution Imaging Spectroradiometer (MODIS) observations in conjunction with an atmospheric dataset. Given a polynya boundary and an atmospheric dataset, the model correctly reproduces the shape of an $\mathbf{1 1}$ day long event, using only a few simple conservation laws. Ice production is slightly overestimated by the model, owing to an underestimated ice thickness. We achieved best model results with the consolidation thickness parameterization developed by Biggs and others (2000). Observed regional discrepancies between model and satellite estimates might be a consequence of the missing representation of the dynamic of the thin-ice thickening (e.g. rafting). We conclude that this simplified polynya model is a valuable tool for studying polynya dynamics and estimating associated fluxes of single polynya events.
\end{abstract}

\section{INTRODUCTION}

Wind-driven flaw polynyas are nonlinear-shaped regions of open water and thin ice within a closed ice cover, formed by offshore winds advecting the pack ice away from fast-ice edges (Smith and others, 1990). In flaw polynyas, large amounts of ice are generated and salt is expelled into the underlying waters (Renfrew and others, 2002; Morales Maqueda and others, 2004). As Arctic sea-ice volume shrinks rapidly (Haas and others, 2008; Kwok and others, 2009), the monitoring of ice production within Arctic polynyas with satellites and models is a crucial objective of ongoing polar research.

Passive microwave satellites allow for a direct deduction of polynya area and, together with atmospheric data, a retrieval of thin-ice thickness and ice production. With their global coverage and their ability to penetrate cloud cover, passive microwave sensors can be used for long-term and large-scale monitoring of polynya dynamics and associated ice formation (Tamura and others, 2007; Kern, 2009; Willmes and others, in press). Unfortunately, the accuracy of the retrieval method depends on regional particularities of polynya size and shape. The coarse spatial resolution of passive microwave satellite data, if applied to narrow polynyas, generates errors through mixed signals at the fastand pack-ice edges (Willmes and others, 2010), and results in an underestimation of ice production.

Thus, monitoring of ice production in narrow leads and polynyas remains difficult with satellites alone. This gap may be filled by flux models capable of simulating polynya evolution and ice fluxes. Flux balance models were first formulated by Pease (1987), embracing the idea of Lebedev (1968) that wind-generated polynyas attain a maximum size resulting from a balance between the flux of frazil ice produced in the open-water area and the wind-driven offshore divergence of consolidated new ice. If fluxes are not in balance, the polynya area is evolving.

Questions still remain as to the consistency and accuracy of flux model assessments. Markus and Burns (1995) found that the area of a polynya retrieved from passive microwave data agreed reasonably well with area estimates made by a one-dimensional (1-D) polynya flux model. These good agreements were confirmed by Haarpaintner and others (2001) and Skogseth and others (2004), who compared flux simulations in the Storfjorden (Svalbard) polynya with icearea and ice-drift information obtained from synthetic aperture radar (SAR) images. The estimation of ice and salt fluxes in polynyas requires, besides correct representation of the polynya extent, an accurate determination of ice growth in both open-water and thin-ice zones. However, a direct comparison of ice-production estimates made by flux models with satellite-based approximations is still missing.

The aim of this paper is therefore to test whether flux models provide realistic ice-production estimates and consequently are capable of filling the gap in narrow-lead and polynya ice-production monitoring.

Below we apply a two-dimensional (2-D) flux model developed by Morales Maqueda and Willmott (2000) to simulate ice production of an 11 day polynya event that took place in the southern Laptev Sea, Russia, in late December 2007. Model results are compared to ice-thickness and iceproduction estimates calculated using high-resolution thermal infrared satellite data obtained from the Moderate Resolution Imaging Spectroradiometer (MODIS) in conjunction with an atmospheric dataset (Riggs and others, 2003; Yu and Lindsay, 2003). The approach is limited to clear-sky conditions, but yields good results for ice thicknesses less 


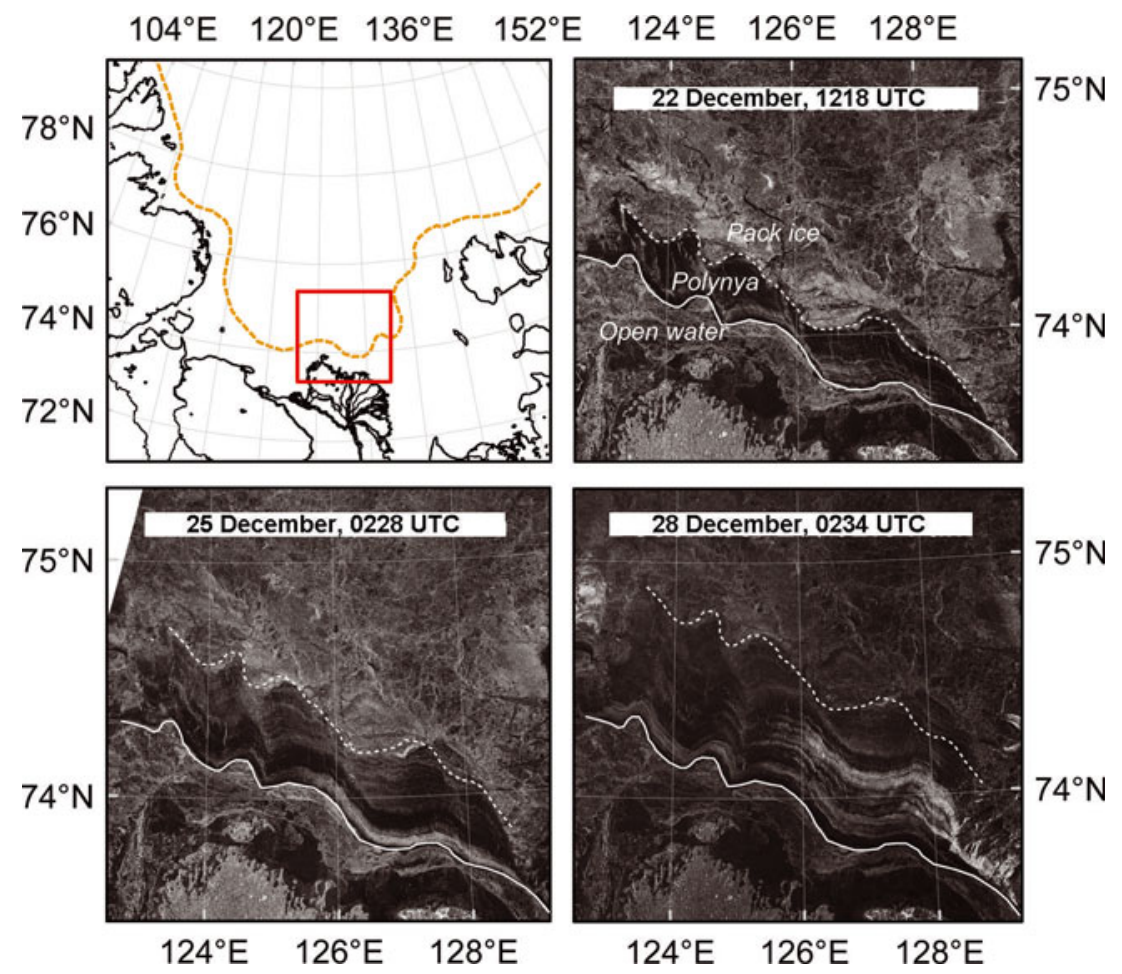

Fig. 1. The upper left panel shows the Laptev Sea and mean recurrent coastal polynya locations (orange line). The red box represents the footprint of three Envisat SAR images, shown in the upper right, lower left and lower right panels. The scenes were acquired between 21 and 28 December 2007, and cover the position of the Anabar-Lena polynya, showing the fast-ice belt (south of white line), the active polynya zone and a region of freely floating pack ice (north of dashed white line).

than $0.5 \mathrm{~m}$ (Willmes and others, 2010). Based on the comparison, we evaluate model applicability and identify mechanisms in the model that are fairly well represented or require further adjustments.

\section{MATERIAL AND METHODS}

Below, we briefly introduce the concept of the 2-D timedependent polynya flux model, the methodology to derive ice production from thermal infrared satellite data and the applied atmospheric dataset. The polynya event was chosen based on MODIS and Envisat SAR observations. In late December 2007, 11 days of offshore winds and low temperatures led to the formation of a wide coastal polynya, located directly north of the Lena Delta, Russia: the Anabar-Lena polynya. Fast-ice and pack-ice edges and the polynya area are easily identifiable in SAR images in Figure 1. The Envisat C-band wide-swath data are VVpolarized and cover an area of $\sim 400 \times 800 \mathrm{~km}^{2}$ with a spatial resolution of $150 \times 150 \mathrm{~m}^{2}$. According to SAR observations, the thin ice formed during 11 days of offshore winds covering $\sim 3.5 \%$ of the area of the Laptev Sea. Because relatively calm wind conditions, combined with low air temperatures, limited the development of large open-water areas, passive microwave sea-ice concentration data reveal no or only minor polynya activity.

\subsection{Model description}

The applied 2-D flux model was developed by Morales Maqueda and Willmott (2000) to simulate the location and temporal evolution of wind-driven polynyas. This model builds upon earlier 1-D unsteady and 2-D steady theories (Pease, 1987; Darby and others, 1994, 1995; Willmott and Morales Maqueda, 1997).
The model distinguishes between two regions in a winddriven polynya (Fig. 2). Region 1 is the area of open water where frazil ice is formed. Region 2 is the thin-ice area. Region 2 starts where the frazil ice, arriving from region 1, consolidates to a new ice layer, and ends at the first-year ice pack. The term polynya includes both the open-water area and the thin-ice zone. The boundary between regions 1 and 2 is termed the 'open-water edge'.

The open-water edge is represented by a curve $C(\mathbf{R}, t)=0$, where $\mathbf{R}$ is the position vector of a point on the open-water edge. From Morales Maqueda and Willmott, (2000) the evolution of point $\mathbf{R}$ is determined by

$$
\frac{\partial \mathbf{R}}{\partial t}=\frac{H \mathbf{U}-h_{c} \mathbf{u}}{H-h_{c}},
$$

where $h_{c}$ and $\mathbf{u}$ are the thickness and velocity of frazil ice arriving at the edge, $C . H$ is the thickness of the consolidated ice formed when the frazil ice 'piles up' against $C$, while $\mathbf{U}$ is the drift velocity of the consolidated new ice.

According to Morales Maqueda and Willmott (2000), the evolution of $H, \mathbf{U}, h_{c}$ and $\mathbf{u}$ is determined as follows. When the wind blows offshore, the pack ice drifts away from the fast-ice edge and open water is formed. Within the openwater zone, frazil ice formation takes place. Following Martin and Kauffman (1981), the frazil ice production in the open-water area is calculated by

$$
\frac{\partial h}{\partial t}=\frac{-Q_{\text {net }}}{\rho_{\mathrm{f}} L_{\mathrm{s}}},
$$

where $\rho_{\mathrm{f}}$ is the frazil ice density of $950 \mathrm{~kg} \mathrm{~m}^{-3}$ (Martin and Kauffman, 1981) and $L_{s}=234.14 \mathrm{~kJ} \mathrm{~kg}^{-1}$ is the latent heat of fusion for sea ice (Yen and others, 1991). The surface heat balance, $Q_{\text {net, }}$ can be decomposed as

$$
Q_{\mathrm{s}}+Q_{\mathrm{l}}+Q_{\mathrm{lw}}+(1-\alpha) Q_{\mathrm{sw}}=Q_{\text {net }},
$$




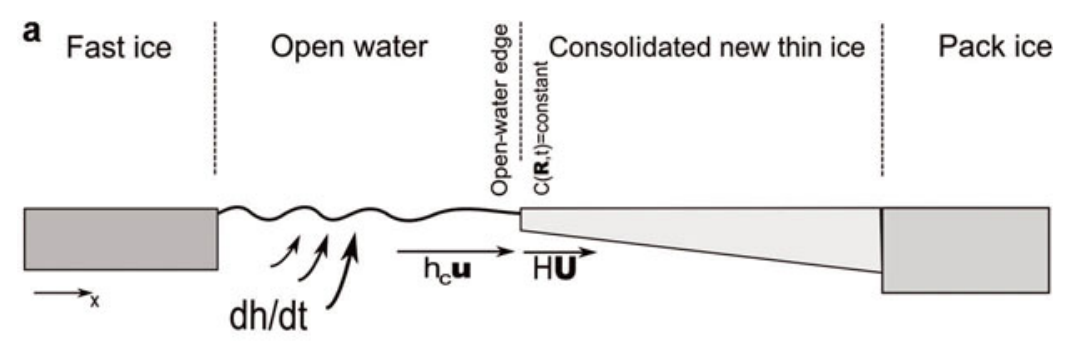

b

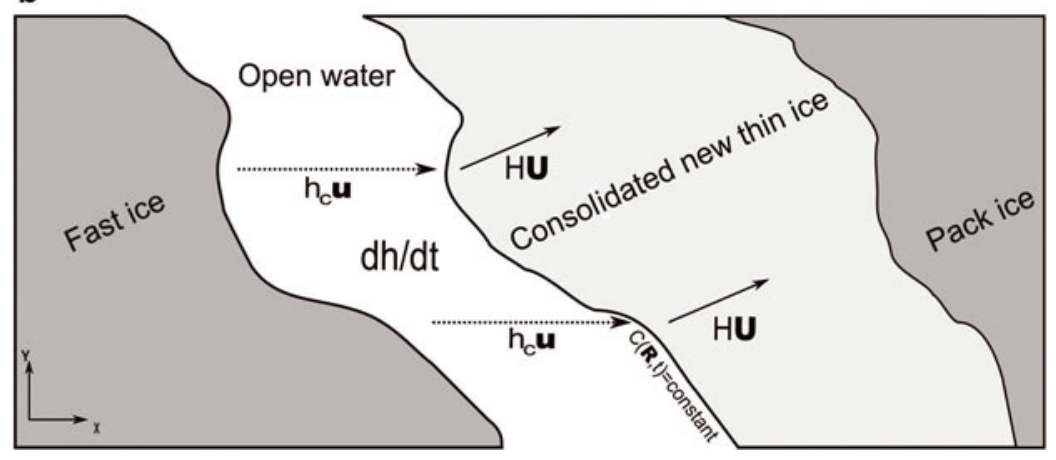

Fig. 2. Schematic drawing illustrating the polynya model in the 1-D (a) and 2-D (b) cases (adapted from Willmott and Morales Maqueda, 1997). In the open-water area, frazil ice grows with rate $\partial h / \partial t$, and is then herded downwind with speed $\mathbf{u}$, until it arrives with thickness $h_{c}$ at the open-water edge, $C(\mathbf{R}, t)=$ constant. Here it piles up to a thickness $H$, and then drifts as consolidated ice away from the edge with speed $\mathbf{U}$.

where $Q_{\mathrm{s}}$ and $Q_{\mathrm{l}}$ are the turbulent sensible and latent heat fluxes calculated using a bulk parameterization with a transfer coefficient of $2.0 \times 10^{-3}$ (Cavalieri and Martin, 1994; Morales Maqueda and others, 2004), $Q_{\text {Iw }}$ is the net longwave radiation of the sea surface, $Q_{\mathrm{sw}}$ is the shortwave solar radiation and $\alpha$ is the surface albedo (Cavalieri and Martin, 1994; Haarpaintner and others, 2001; Morales Maqueda and others, 2004). If $Q_{\text {net }}$ is negative, the water body emits heat to the atmosphere and frazil ice is produced. In late December, the incoming solar radiation and the heat flux due to precipitation can be neglected. The atmospheric forcing is assumed to be uniform over regions 1 and 2 .

After formation, Langmuir circulation, created by the interaction of the waves with the wind stress, herds frazil ice into slurries taking the form of long bands or plumes. Wind pushes the long bands of grease ice downwind (Pease, 1987; Martin, 2001). The velocity, u, of the frazil ice drift is determined following Martin and Kauffman (1981). The effect of surface currents on the frazil ice drift trajectories is neglected.

At the open-water edge, $h_{c}$ consolidates to a thin-ice layer with thickness $H$. We apply the parameterization for $H$ developed by Biggs and others (2000) to avoid situations where $h_{c}$ becomes larger than $H$. Following Biggs and others (2000), $H$ is derived in terms of the depth of frazil ice arriving at $C$ and the component, normal to $C$, of the frazil ice velocity relative to the velocity of the consolidated new ice.

After consolidation, the continuous thermodynamic growth of new ice formed is calculated by Stefan's law (Maykut, 1986; Petrich and Eicken, 2009). Through some simplifications, the so-called degree-day model can make a fairly accurate prediction of sea-ice growth. The drift of the new ice is determined by Zubov's law (Leppäranta, 2005). The occurrence of rafting inside the thin-ice area is not taken into account.

For a comprehensive description of the model and numerical methods employed, we refer the reader to
Morales Maqueda and Willmott (2000) and Willmott and others (2007).

\subsection{Thermal infrared satellite data}

We use level 1B calibrated radiances (thermal infrared) from the MODIS sensor, provided by the NASA Level 1 and Atmosphere Archive and Distribution System (LAADS), to derive ice surface temperatures from brightness temperatures at 11 and $12 \mu \mathrm{m}$ (MODIS channels 31 and 32, respectively; Riggs and others, 2003). The spatial resolution of the sensor is approximately $1 \times 1 \mathrm{~km}^{2}$. The MODIS cloud mask (MOD35) product is used at the 'confident clear' level to determine clear-sky regions and to avoid a potential temperature bias due to sea smoke.

Following Yu and Lindsay (2003), the thermal thin-ice thickness, $h_{\text {th, }}$ is inferred from the obtained ice surface temperatures, $T_{\mathrm{s}}$, by

$$
h=\frac{k_{\mathrm{i}}\left(T_{\mathrm{s}}-T_{0}\right)}{Q_{\mathrm{net}}}
$$

where $T_{0}=-1.86^{\circ} \mathrm{C}$ is the sea-water temperature at freezing point and $k_{\mathrm{i}}=2.03 \mathrm{~W} \mathrm{~m}^{-1} \mathrm{~K}^{-1}$ is the thermal conductivity of sea ice (Drucker and others, 2003). $Q_{\text {net }}$ is calculated from Equation (3), with the same parameterizations as used for the model. The thickness retrieval is based on the assumption that the heat flux through the ice equals the total atmospheric heat flux. The method implies that vertical temperature profiles within the ice are linear and no snow is present on top. It yields good results for ice thicknesses less than $0.5 \mathrm{~m}$, for which its accuracy is estimated to be $\pm 20 \%$ (Drucker and others, 2003).

In total, we identified 67 MODIS scenes, covering the Anabar-Lena polynya between 20 and 30 December 2007. The study period is characterized by very low cloud coverage and the absence of snowfall, such that surface temperature composites could be assembled on a daily basis, except for 29 December. 


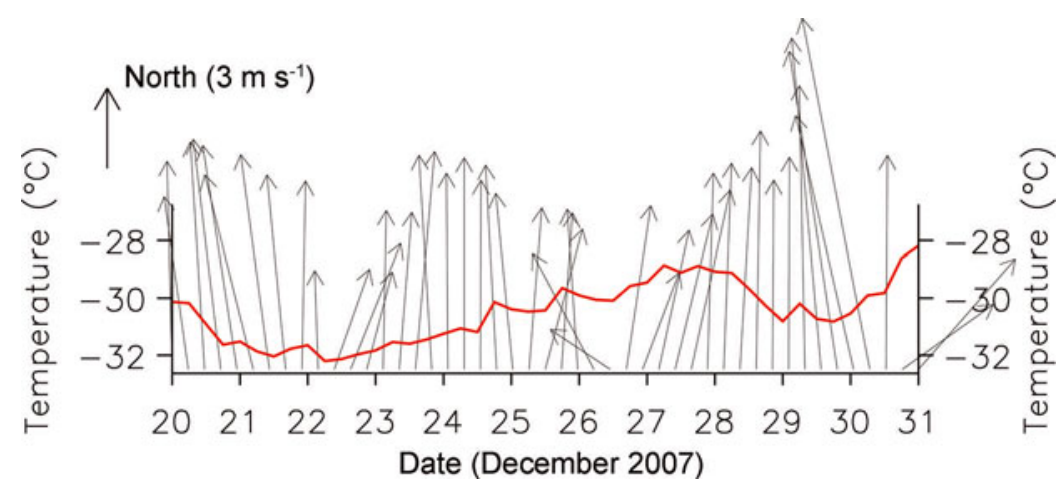

Fig. $3.2 \mathrm{~m}$ air temperatures and $10 \mathrm{~m}$ wind vectors during the study period, taken from atmospheric dataset. Wind vectors show the direction of airflow, with their lengths representing wind speed.

Assuming that surface heat loss is entirely used for ice formation, the ice production for ice thinner than $0.5 \mathrm{~m}$ is determined by

$$
\frac{\partial h}{\partial t}=\frac{-Q_{\text {net }}}{\rho_{\mathrm{i}} L_{\mathrm{s}}},
$$

where $\rho_{\mathrm{i}}=920 \mathrm{~kg} \mathrm{~m}^{-3}$ is the density of thin ice. Willmes and others (2010) provide a detailed description of ice-thickness retrieval from surface temperature information.

\subsection{Atmospheric data}

Model and MODIS computations are based on 6 hourly analysis data from the global numerical weather prediction model, GME, of the German Weather Service (Majewski and others, 2002). Mean sea-level pressure, $2 \mathrm{~m}$ air temperature and humidity and $10 \mathrm{~m}$ wind vector were extracted from a single gridpoint in the centre of the polynya (Fig. 3). The applicability of the analyzed data is shown by a comparison with automatic weather stations (Schröder and others, in press).

\section{RESULTS}

The evolution of open water and thin ice, and associated ice production was simulated with the polynya flux model. Model results were interpolated to a grid with a spacing equal to the spatial resolution of the MODIS sensor. The drift algorithm for consolidated ice (Zubov's law) requires the icedrift deviation angle from the wind direction and ice-drift velocity in per cent of wind velocity to be known. These constants were taken from SAR images (Haarpaintner and others, 2001). The model boundary is the fast-ice edge. Broken fast-ice pieces at the polynya edge hamper comparison of model results with MODIS thermal estimates. Hence, we restrict comparison to the $100 \mathrm{~km}$ wide polynya centre covered solely by thin ice. The area is located between $124^{\circ} \mathrm{E}$ and $127^{\circ} \mathrm{E}$. The method to infer thermal infrared thickness and production is restricted to ice thinner than $0.5 \mathrm{~m}$. We therefore limit the model evaluation to this thermal range $(0-0.5 \mathrm{~m})$. Model thicknesses and resultant ice production exceeding $0.5 \mathrm{~m}$ are excluded from comparison. Note that for 29 December a MODIS composite is not available. For this particular date, we interpolate between satellite approximations made on 28 and 30 December.

Figure 4 shows flux model results and satellite estimates for 25 December. Polynya ice-thickness distribution and ice production were computed from MODIS data and model results. A SAR image taken on 25 December at 0228 UTC
(Fig. 1) shows the areal extent of the polynya. The banded zones of high and low backscatter between the fast-ice edge and pack ice correspond to young ice, formed between 20 and 25 December. These patterns are partially preserved in thermal MODIS ice-thickness information. The mean thickness for the polynya area below $0.5 \mathrm{~m}$ is $0.32 \mathrm{~m}$, with minimum ice thicknesses of $0.04 \mathrm{~m}$. The ice area adjacent to the pack-ice edge (cf. SAR scene) is thicker than $0.5 \mathrm{~m}$, and consequently not included in the thermal approach. The mean model polynya thickness is lower $(0.27 \mathrm{~m})$, and the maximum thickness does not exceed $0.4 \mathrm{~m}$. According to Figure 4, the agreement between MODIS and model ice production is high and the shape of the polynya is well resolved by the model. Note that the opening event is not visible in sea-ice concentration data derived from the Advanced Microwave Scanning Radiometer (AMSR-E).

Below, we compare satellite and model polynya area evolution, thickness distribution and ice-production rates for ice thinner than $0.5 \mathrm{~m}$.

The polynya area evolution, as retrieved from model, MODIS and Envisat SAR estimates, is presented in Figure 5. The thermal and model area estimates show the evolution of ice areas thinner than $0.5 \mathrm{~m}$. In contrast, SAR area estimates include, based on a visual image segmentation, the entire thin-ice area formed between fast ice and the pack-ice edge during 11 days of polynya activity (see Fig. 1).

According to the last SAR image available before the end of the observation period, the areal extent of the polynya reaches $\sim 7.9 \times 10^{3} \mathrm{~km}^{2}$. This corresponds to an average opening width of $87 \mathrm{~km}$. During the first 8 days of offshore winds (see Fig. 3), polynya area continuously increases regardless of the methodology used for area calculation. MODIS area approximations are slightly lower than SAR area estimates, since the thickness of thin ice close to the pack-ice edge is beyond the limit of the thermal icethickness retrieval. Ice growth beyond $0.5 \mathrm{~m}$ also causes the sharp drop in MODIS area from $4.8 \times 10^{3} \mathrm{~km}^{2}$ down to $1.1 \times 10^{3} \mathrm{~km}^{2}$ between 28 and 30 December. Model thinice areas exceed ice thicknesses of $0.5 \mathrm{~m}$ only at the very end of the observation period. Hence, the model area closely follows SAR area estimates.

A direct comparison of the computed open-water area with satellite approximations is not possible, since reliable satellite-based open-water estimates are missing. In SAR images, often no clear limit exists between open water and consolidated thin ice, due to the smooth transition from low to high frazil ice concentration. MODIS-based open-water estimates suffer from mixed pixel signatures. Following 

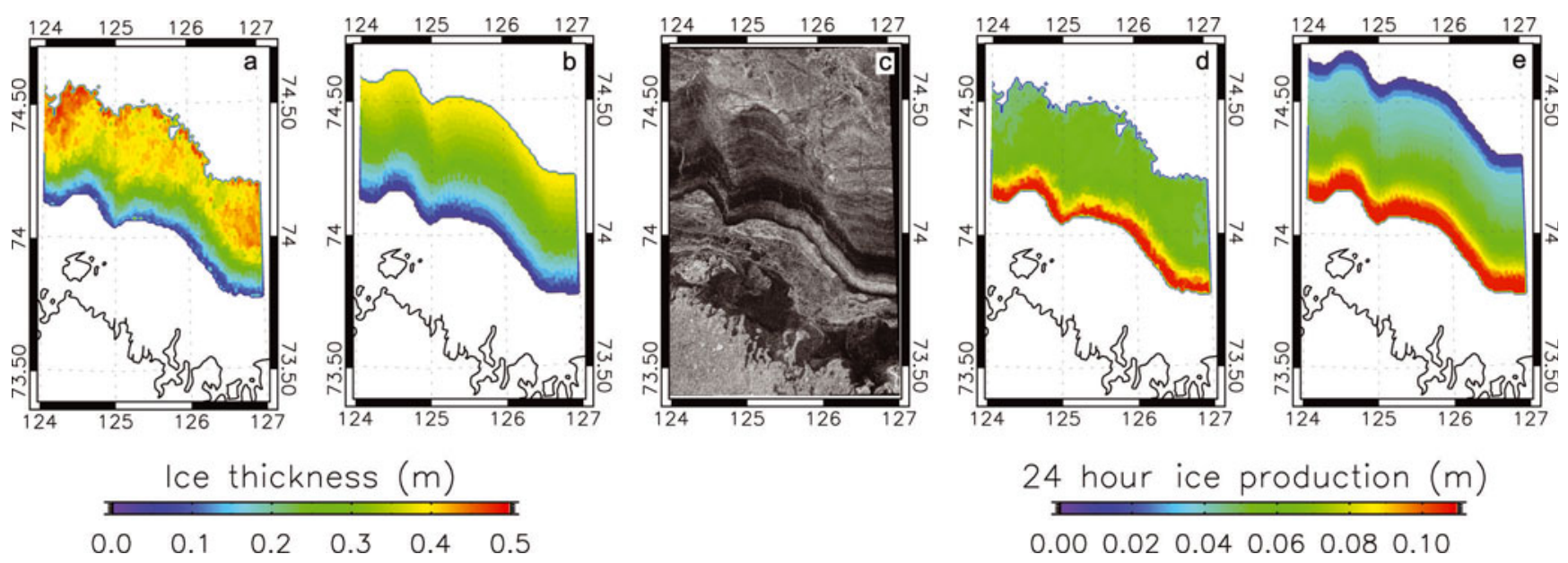

Fig. 4. Polynya flux model results and satellite estimates for 25 December. $(a, b)$ Ice-thickness distribution inside the thin-ice area, from MODIS approximations (a) and model (b). (c) A SAR scene, taken at 0002 UTC. (d, e) Satellite-based (d) and modelled (e) daily ice volume production.

Equation (4), open-water areas are characterized by a surface temperature close to the freezing point of sea water. Unfortunately, the presence of frazil ice, Langmuir streaks or ice floes in the water column lowers the averaged surface temperature within the sensor footprint beneath freezing point, such that potential open-water areas are classified as very thin ice.

Figure 6 shows the zonally averaged ice-thickness profile across the polynya and its standard deviation, computed from MODIS composites and model results for 9 days of polynya activity. Both MODIS and model show an increase in ice thickness with increasing distance from the fast-ice edge. The simulated ice thickness tends to be generally lower than thermal ice thickness. Standard deviations are higher for thermal ice thicknesses than for model thickness.

Near the fast-ice edge, the model shows a small strip of open water with ice thickness equal to 0 . Within this zone, ice growth in the model takes place as frazil ice formation, which is herded offshore until it consolidates at the openwater edge. Following the parameterization developed by Biggs and others (2000), the consolidation thickness varies between $6 \mathrm{~cm}$ (27 December) and $15 \mathrm{~cm}$ (25 December). After consolidation, the ice thickness in the model is governed by thermodynamic processes as described by Stefan's law (Petrich and Eicken, 2009).

The MODIS sensor does not show open-water zones. Instead, the zone close to the fast-ice edge is characterized by

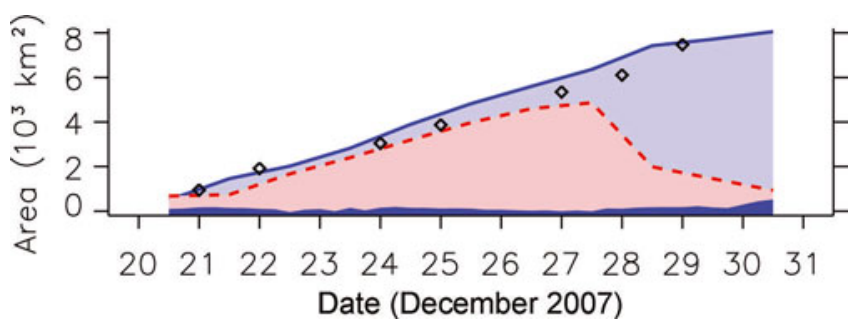

Fig. 5. Total polynya area (light-blue shaded) and open-water fraction (blue shaded) calculated with the flux model. MODISbased polynya area estimates are presented in the red shaded area. Diamonds show area information taken from Envisat SAR images. very low thicknesses varying between $6 \mathrm{~cm}$ (30 December) and $20 \mathrm{~cm}$ (22 December). With increasing distance from the fast-ice edge, the difference in MODIS and model estimates decreases, except for 21 and 22 December.

Figure 7 shows the zonally averaged ice production across the polynya computed from MODIS and model results. Modelled ice production agrees well with MODIS estimates. At the fast-ice edge, highest ice-production rates are achieved, either in the form of frazil ice production (model), or by means of conductive heat flux through very thin ice (MODIS; Fig. 6). Ice production then decreases with distance from the fast-ice edge, owing to the increasing ice thickness. Largest deviations in MODIS and model ice production estimates occur $0-10 \mathrm{~km}$ offshore of the fast-ice edge.

The accumulated total ice production over 11 days in the entire polynya area is presented in Figure 8. Because modelled ice thickness exceeds $0.5 \mathrm{~m}$ only at the end of

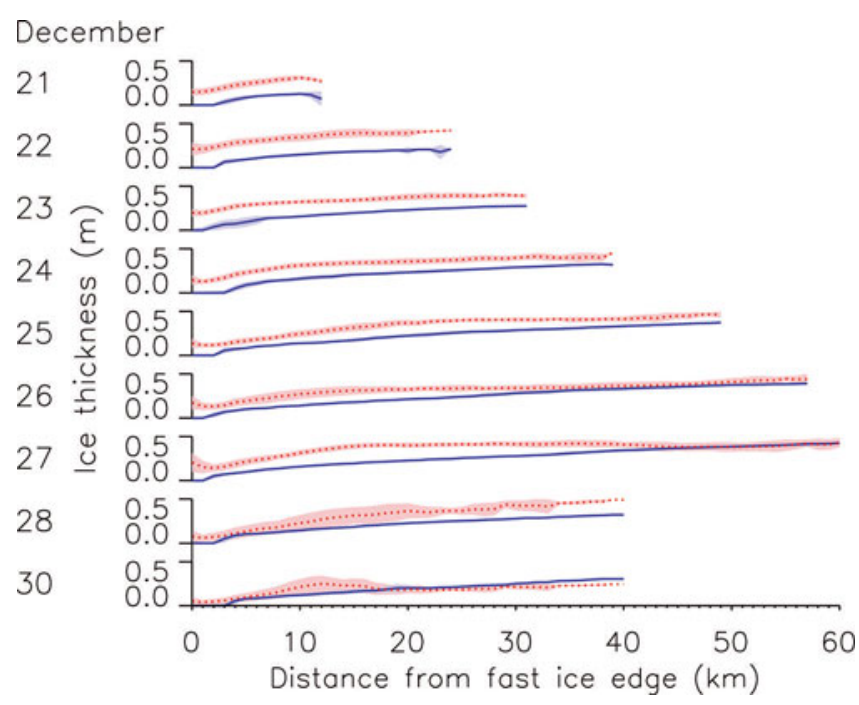

Fig. 6. Zonally averaged polynya ice-thickness distribution as a function of distance from fast-ice edge for 9 days of polynya activity. The red dotted curve represents MODIS thermal ice thickness, and the blue solid curve flux model estimations. Corresponding shaded areas indicate one standard deviation from mean thickness. 


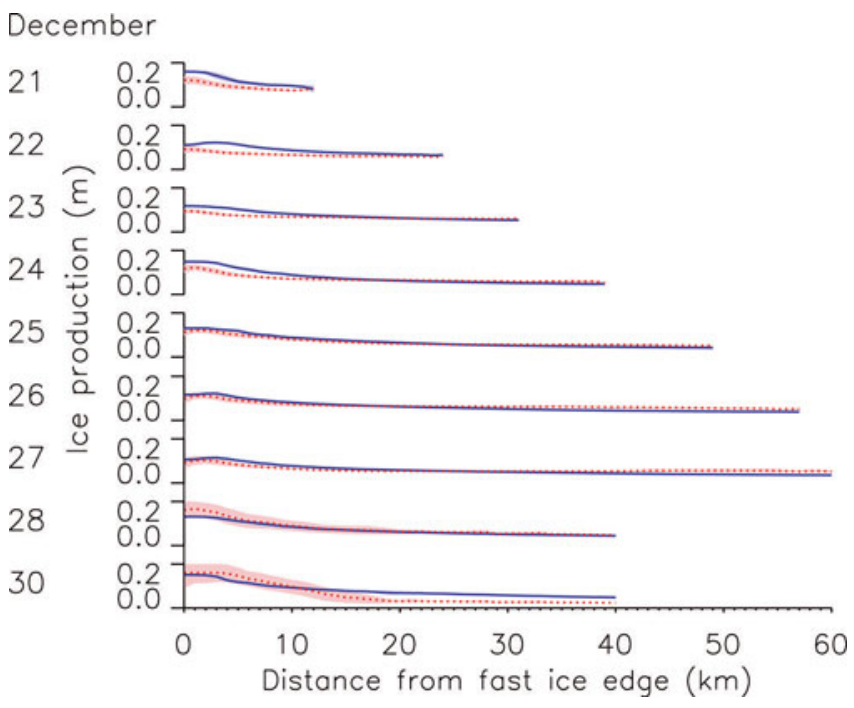

Fig. 7. Zonally averaged 24 hour ice volume production as a function of distance from fast-ice edge for 9 days of polynya activity. The red dotted curve corresponds to ice production as derived from MODIS. The blue solid curve represents flux model estimations. Corresponding shaded areas indicate one standard deviation from mean thickness.

the observation period, its ice-production area extends far north (see also Fig. 5). MODIS and the flux model calculate the accumulated ice production per $\mathrm{km}^{2}$ in the area near the fast-ice edge to be 1.3 and $1.2 \mathrm{~m}$, respectively. Beyond the fast-ice edge region, ice formation rates are higher in the model, because of lower ice-thickness estimates (Fig. 6). The mean accumulated ice production per $\mathrm{km}^{2}$ is 0.4 and $0.37 \mathrm{~m}$, for MODIS and model respectively. The satelliteobserved characteristics of ice production are well captured by the model.

Figure 9 presents the MODIS and model mean daily and accumulated total ice production. Calculations in the upper panel are limited to an area of $900 \mathrm{~km}^{2}$ adjacent to the fastice edge. This area includes open water and parts of the thinice zone. The extent of the mask area is drawn in Figure 8 and is equivalent to the polynya area 1.5 days after opening. During the first 8 days, the modelled mean daily and accumulated total production slightly exceeds MODIS estimates. However, an increase in MODIS ice production on 28 and 30 December causes the accumulated ice volumes to converge towards the end of the observation period. The total ice production inside the mask area is $0.9 \mathrm{~km}^{3}$.

In the lower panel, all ice areas thinner than $0.5 \mathrm{~m}$ were taken into account for volume approximations. Again, at the beginning the model shows a higher daily mean production, until on 28 December the MODIS polynya area decreases owing to an increase in ice thickness beyond $0.5 \mathrm{~m}$ (Fig. 5). As a consequence, modelled daily ice production becomes twice as high as MODIS estimates, resulting in a $30 \%$ higher total ice volume.

\section{DISCUSSION}

The determination of the open-water edge is a central element in the model concept. Unfortunately, the reliability of the modelled open-water width is difficult to assess directly, since for the prescribed situation satellite-based open-water width estimates are missing. This is because the

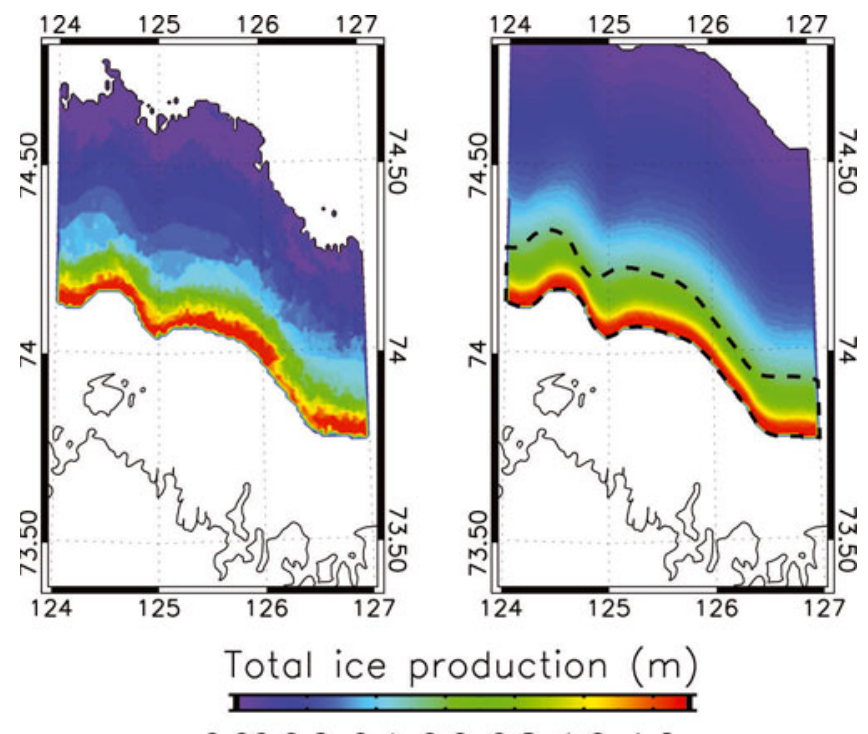

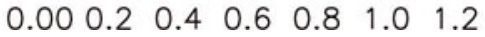

Fig. 8. Total amount of ice produced in 11 days of polynya activity (20-30 December 2007). Left panel: ice production based on MODIS thermal infrared data. Right panel: model-simulated ice production. In the area near the fast-ice edge the accumulated ice production amounts to $1.3 \mathrm{~m}$ (MODIS) and $1.2 \mathrm{~m}$ (flux model). The dashed black line shows the extent of the mask area applied in Figure 9.

identification of open water in SAR and MODIS scenes is hampered by the narrowness of the open-water zone and the presence of frazil ice in the water column.

Nevertheless, since ice-production rates are highest inside the open-water area, the spatial distribution of highly productive zones indicates the extent of open water. Consequently, the achieved accuracy of the open-water simulation can be determined through a comparison of satellite-based estimates with modelled zones of high icegrowth rates. Moreover, good agreement between modelled

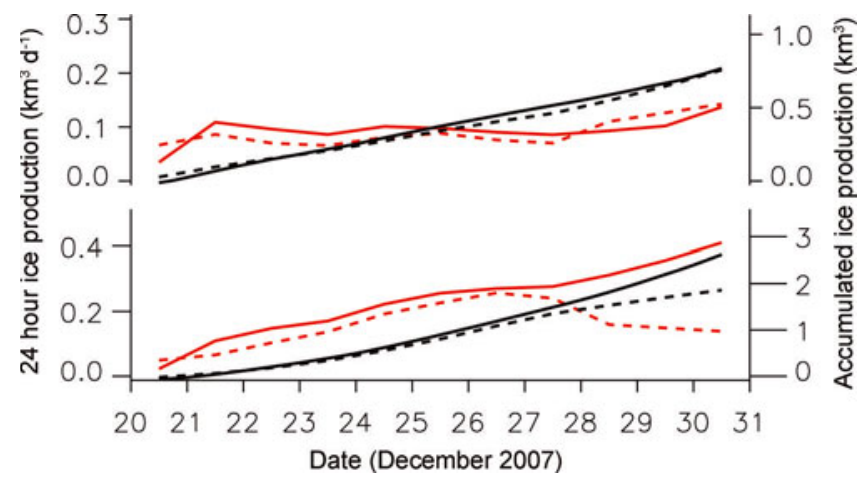

Fig. 9. MODIS and model mean daily and accumulated total ice production between 20 and 30 December 2007. Upper panel: Mean daily and accumulated total ice production within a predefined $900 \mathrm{~km}^{2}$ area offshore the fast-ice edge (mask area is shown in Fig. 8). Modelled and thermal mean daily ice production are represented by the solid red and dashed red curves, respectively (left axis). Modelled and thermal accumulated total ice production are represented by the solid black and dashed black curves, respectively (right axis). Lower panel: Mean and accumulated total ice production for the entire polynya area. The color and line code are the same as in the upper panel. 
and thermal ice-thickness distribution is a second indication for model reliability.

An initial comparison of thermal infrared ice-thickness and -production estimates with model computations has shown that the flux model reproduces quite well the shape of the polynya and salient features of the landfast ice boundary.

Note that the equations to derive ice thickness and ice production from MODIS are, by definition, very close to the equations used in the model. In addition, the applied atmospheric forcing is identical. Hence, the accuracy of the simulation primarily depends on whether a realistic fast-ice boundary is used and whether the movement of the pack-ice edge is prescribed correctly (by estimating appropriate parameters for Zubov's law from SAR images). Another well-known uncertainty in polynya simulations is the parameterization of the collection depth, $H$, to which the evolution of the open-water edge is extremely sensitive. Early 1-D and 2-D polynya flux models used constant values for $H$, typically 0.02-0.3 m (Martin and Kauffman, 1981; Pease, 1987; Morales Maqueda and Willmott, 2000; Haarpaintner and others, 2001), chosen by fitting flux model results to the observed widths of the open-water zone. Winsor and Björk (2000) assume $H$ to be a linear function of the $10 \mathrm{~m}$ wind speed, increasing from 10 to $30 \mathrm{~cm}$ as the wind speed increases from 5 to $35 \mathrm{~m} \mathrm{~s}^{-1}$. Biggs and others (2000) developed a parameterization to avoid situations where the thickness of frazil ice arriving at the polynya edge exceeds $H$. All different parameterizations for $H$ were tested in the model and results were compared to satellite approximations (not shown here). For the event investigated in this paper, we found that the parameterization developed by Biggs and others (2000) yields the most realistic open-water extent. Parameterizations using constant $H$ are either numerically unstable or lead to a crude overestimation of open-water area.

Furthermore, regional differences between satellite estimates and model results are related to the representation of physical processes in the model and possible deficiencies in the atmospheric datasets. Below, we discuss parameterizations and mechanisms that are fairly well represented or require further adjustments.

Because the GME dataset is spatially quite uniform, we use atmospheric forcing fields extracted from a single gridpoint in the centre of the polynya. The mean deviation in alongshore wind velocity from the polynya centre is $0.4 \pm 0.21 \mathrm{~m} \mathrm{~s}^{-1}$. The average alongshore differences in wind direction and temperature are $4.4 \pm 3.1^{\circ} \mathrm{C}$ and $0.34 \pm 0.32^{\circ} \mathrm{C}$, respectively. The resultant uncertainty in heat-flux computations is $35 \pm 30 \mathrm{~W} \mathrm{~m}^{-2}$, which is equivalent to a frazil ice production error of $1.1 \pm 0.9 \mathrm{~cm} \mathrm{~m}^{-2} \mathrm{~d}^{-1}$. In reality, however, strong gradients of air temperature and wind speed across and along the polynya may exist which are not captured by the GME dataset and which may lead to uncertainties in ice-production estimates. Furthermore, in the atmospheric GME model, polynyas are not present, so the $2 \mathrm{~m}$ air temperatures are valid over thin ice only. Following Ebner and others (in press), $2 \mathrm{~m}$ air temperatures over open water can be significantly higher than over the ice. This may result in an overestimation of both modelled and satellite-based ice production.

Some physical processes that do have an impact on the formation and maintenance of the polynya are not considered in the model. There is evidence that frazil ice trajectories are affected by ocean currents (Willmott and Morales Maqueda, 1997). In the flux model, we assume frazil ice motion to be purely wind-driven, since the strength and direction of near-surface currents are unknown. In addition, inertial motions and tidal currents might advect warmer water from outside into the polynya area, thus hindering frazil ice production (Willmott and Morales Maqueda, 2007). The error associated with this uncertainty is unknown.

The simplifications made in the model become increasingly important as the open-water region grows in size. In our case, the simulated polynya develops under moderate wind speeds and low air temperatures, such that the openwater area stays relatively small. If the open-water width increases, which is the case for polynya events in the Laptev Sea taking place in late April (Willmes and others, 2010), spatial variations in atmospheric and oceanic forcing will significantly alter frazil ice motion.

Besides the parameterization of $H$, discrepancies between satellite estimates and model can also be a consequence of the incomplete, or missing, representation of dynamic processes taking place inside the thin-ice area. According to Skogseth and others (2005), rafting and ridging in polynyas can play a significant role in ice thickening, the creation of open-water area and ice production. Rafting and ridging primarily result from a compression of the thin-ice zone, owing to differences between the drift of the outer pack ice and the evolution of the open-water edge.

During the opening of the Anabar-Lena polynya, we assume that compression results exclusively in rafting. This assumption is supported by aerial photographs taken on winter expeditions in the Laptev Sea during different flights across active polynyas (Transdrift XIII, Transdrift XV). The aerial images show that the occurrence of rafting increases with distance from the fast ice. This is because, at the onset of an opening event, when the thin-ice zone is rather small, compression operates on a relatively small thin-ice area, leading to high rafting rates. With increasing thin-ice width, the rafting probability weakens. This possibly explains the decrease in discrepancies between satellite approximations and model results towards the end of the observation period. To account for rafting in the model, one could simulate the evolution of the outer pack ice and open-water edge separately and take the difference between drifts as a measure of compression acting on the thin-ice zone. Nevertheless, an implementation of a dynamic thickening component is difficult, since studies on rafting probabilities in thin-ice zones are limited to characterizations of processes such as energy consumption (Worby and others, 1996; Babko and others, 2002).

The spatial and quantitative agreement between modelled and satellite-based total ice volume production is high (Fig. 8). The largest deviations in ice-production estimates coincide with areas of high disparity between simulated and thermal infrared thickness (Figs 6, 7 and 9). If we limit satellite and model comparison to the highly productive zone close to the fast-ice edge (masked area in Fig. 8 and upper panel of Fig. 9), differences in ice volume calculations are even smaller. Taking into account the entire polynya area (lower panel of Fig. 9), the model overestimates ice production by $30 \%$. This is due to the differences in simulated and satellite-based polynya area estimates (Fig. 5), which is, again, a consequence of the underestimated model ice thickness. 


\section{CONCLUSION}

We have compared two approaches commonly used to estimate ice production by applying them to an observed Laptev Sea polynya event. A 2-D flux model developed by Morales Maqueda and Willmott (2000) is used to calculate the location of the transition between open water and thin ice, the drift of consolidated new ice and associated ice formation. Results from this model are in agreement with ice-thickness and -production estimates obtained from MODIS thermal infrared data in conjunction with an atmospheric dataset.

Given a polynya boundary (coastline or fast-ice edge) and an atmospheric dataset, the model is capable of describing the shape of the polynya realistically using only a few simple conservation laws. The mean accumulated ice production per unit area for 11 days of polynya activity is 0.4 and $0.37 \mathrm{~m}$ for thermal and model estimates, respectively. The accumulated ice production in the area near the fast-ice edge amounts to 1.3 and $1.2 \mathrm{~m}$, respectively. Further offshore, iceformation rates are overestimated by the model because it underestimates the ice thickness.

We conclude that this simplified physical polynya model is a valuable tool for studying polynya dynamics and estimating associated fluxes of single polynya events. It provides an alternative to passive microwave polynyamonitoring techniques, which are often not capable of resolving narrow polynyas formed under moderate or low wind forcing.

The best model results are achieved with the consolidation thickness parameterization developed by Biggs and others (2000). The implementation of dynamic thin-ice thickening could eventually improve observed regional discrepancies between model and satellite. When simulating polynya events of larger alongshore dimension, the use of a spatially non-uniform forcing dataset would be required. However, with increasing complexity, a purely numerical approach is needed.

\section{ACKNOWLEDGEMENTS}

This work was carried out as part of the German-Russian cooperation 'System Laptev Sea', funded by the Federal Ministry of Education and Research (BMBF), Germany, under grant 03G0639A and the Alfred Wegener Institute. Satellite data were obtained through European Space Agency project EO-500 'Formation, transport and distribution of sediment-laden sea ice in the Arctic Shelf seas'. MODIS images were provided by LAADS/NASA, and AMSR-E ARTIST Sea Ice (ASI) sea concentrations by the University of Bremen, Germany. The GME analyses were made available by the German Weather Service.

\section{REFERENCES}

Babko, O., D.A. Rothrock and G.A. Maykut. 2002. The role of rafting in the mechanical redistribution of sea ice thickness. J. Geophys. Res., 107(C8), 2701-2714.

Biggs, N.R.T., M.A. Morales Maqueda and A.J. Willmott. 2000. Polynya flux model solutions incorporating a parameterization for the collection thickness of consolidated new ice. J. Fluid Mech., 408, 179-204.

Cavalieri, D.J. and S. Martin. 1994. The contribution of Alaskan, Siberian, and Canadian coastal polynyas to the cold halocline layer of the Arctic Ocean. J. Geophys. Res., 99(C9), $18,343-18,362$.
Darby, M.S., A.J. Willmott and L.A. Mysak. 1994. Nonlinear steadystate model of the North Water polynya, Baffin Bay. J. Phys. Oceanogr., 24(5), 1011-1020.

Darby, M.S., A.J. Wilmott and T.A. Somerville. 1995. On the influence of coastline orientation on the steady state width of a latent heat polynya. J. Geophys. Res., 100(C7), 13,625-13,633.

Drucker, R., S. Martin and R. Moritz. 2003. Observations of ice thickness and frazil ice in the St. Lawrence Island polynya from satellite imagery, upward looking sonar, and salinity/temperature moorings. J. Geophys. Res., 108(C5), 3149. (10.1029/ 2001JC001213.)

Ebner, L., D. Schreoder and G. Heinemann. In press. Impact of Laptev Sea flaw polynyas on the atmospheric boundary layer and ice production using idealized mesoscale simulations. Polar Res.

Haarpaintner, J., P.M. Haugan and J.C. Gascard. 2001. Interannual variability of the Storfjorden (Svalbard) ice cover and ice production observed by ERS-2 SAR. Ann. Glaciol., 33, 430-436.

Haas, C., A. Pfaffling, S. Hendricks, L. Rabenstein, J.-L. Etienne and I. Rigor. 2008. Reduced ice thickness in Arctic Transpolar Drift favors rapid ice retreat. Geophys. Res. Lett., 35(17), L17501. (10.1029/2008GL034457.)

Kern, S. 2009. Wintertime Antarctic coastal polynya area: 19922008. Geophys. Res. Lett., 36(14), L14501. (10.1029/ 2009GL038062.)

Kwok, R., G.F. Cunningham, M. Wensnahan, I. Rigor, H.J. Zwally and D. Yi. 2009. Thinning and volume loss of the Arctic Ocean sea ice cover: 2003-2008. J. Geophys. Res., 114(C7), C07005. (10.1029/2009JC005312.)

Lebedev, V.L. 1968. Maximum size of a wind-generated lead during sea freezing. Oceanology, 8, 313-318.

Leppäranta, M. 2005. The drift of sea ice. Berlin, etc., SpringerVerlag.

Majewski, D. and 7 others. 2002. The operational global icosahedral-hexagonal gridpoint model GME: description and high-resolution tests. Mon. Weather Rev., 130(2), 319-338.

Markus, T. and B.A. Burns. 1995. A method to estimate sub-pixelscale coastal polynyas with satellite passive microwave data. J. Geophys. Res., 100(C3), 4473-4487.

Martin, S. 2001. Polynyas. In Steele, J.H., K.K. Turekian and S.A. Thorpe, eds. Encyclopedia of ocean sciences. New York, Elsevier, 55-59.

Martin, S. and P. Kauffman. 1981. A field and laboratory study of wave damping by grease ice. J. Glaciol., 27(96), 283-313.

Maykut, G.A. 1986. The surface heat and mass balance. In Untersteiner, N., ed. Geophysics of sea ice. London, etc., Plenum Press, 395-463. (NATO ASI Series B: Physics 146.)

Morales Maqueda, M.A. and A.J. Willmott. 2000. A twodimensional time-dependent model of a wind-driven coastal polynya: application to the St. Lawrence Island polynya. J. Phys. Oceanogr., 30(6), 1281-1304.

Morales Maqueda, M.A., A.J. Willmott and N.R.T. Biggs. 2004. Polynya dynamics: a review of observations and modeling. Rev. Geophys., 42(1), RG1004. (10.1029/2002RG000116.)

Pease, C.H. 1987. The size of wind-driven coastal polynyas. J. Geophys. Res., 92(C7), 7049-7059.

Petrich, C. and H. Eicken. 2009. Growth, structure and properties of sea ice. In Thomas, D.N. and G.S. Dieckmann, eds. Sea ice: an introduction to its physics, chemistry, biology and geology. Second edition. Chichester, Wiley-Blackwell, 23-77.

Renfrew, I., J.C. King and T. Markus. 2002. Costal polynyas in the southern Weddell Sea: variability of the surface energy budget. J. Geophys. Res., 107(C6), 3063. (10.1029/2000JC000720.)

Riggs, G.A., D.K. Hall and V.V. Salomonson. 2003. MODIS sea ice products user guide. Greenbelt, MD, NASA Goddard Space Flight Center. (NASA Technical Report.)

Schröder, D., G. Heinemann and S. Willmes. In press. Implementation of a thermodynamic sea ice module in the NWP model COSMO and its impact on simulations for the Laptev Sea area in the Siberian Arctic. Polar Res. 
Skogseth, R., P.M. Haugan and J. Haarpaintner. 2004. Ice and brine production in Storfjorden from four winters of satellite and in situ observations and modeling. J. Geophys. Res., 109(C10), C10008. (10.1029/2004JC002384.)

Skogseth, R., I. Fer and P.M. Haughan. 2005. Dense-water production and overflow from an arctic coastal polynya in Storfjorden. In Drange, H., T. Dokken, T. Furevik, R. Gerdes and W. Berger, eds. The Nordic seas: an integrated perspective. Washington, DC, American Geophysical Union, 73-88. (Geophysical Monograph 158.)

Smith, S.D., R.D. Muench and C.H. Pease. 1990. Polynyas and leads: an overview of physical processes and environment. J. Geophys. Res., 95(C6), 9461-9479.

Tamura, T., K.I. Ohshima, T. Markus, D.J. Cavalieri, S. Nihashi and N. Hirasawa. 2007. Estimation of thin ice thickness and detection of fast ice from SSM/I data in the Antarctic Ocean. J. Atmos. Oceanic Technol., 24(10), 1757-1772.

Willmes, S., S. Adams, D. Schröder and G. Heinemann. In press. Spatiotemporal variability of polynya dynamics and ice production in the Laptev Sea between the winters of 1979/80 and 2007/08. Polar Res.

Willmott, A.J. and M.A. Morales Maqueda. 1997. A model for the influence of wind and oceanic currents on the size of a steady-state latent heat coastal polynya. J. Phys. Oceanogr. 27(10), 2256-2275.

Willmott, A.J., D.M. Holland and M.A. Morales Maqueda. 2007. Polynya modelling. In Smith, W.O.J. and D.G. Barber, eds. Polynyas: windows to the world. Amsterdam, etc., Elsevier.

Winsor, P. and G. Björk. 2000. Polynya activity in the Arctic Ocean from 1958 to 1997. J. Geophys. Res., 105(C4) 8789-8803.

Worby, A.P., M.O. Jeffries, W.F. Weeks, R. Morris and R. Jaña. 1996. The thickness distribution of sea ice and snow cover during late winter in the Bellingshausen and Amundsen Seas, Antarctica. J. Geophys. Res., 101(C12), 28,441-28,455.

Yen, Y.C., K.C. Cheng and S. Fukusako. 1991. Review of intrinsic thermophysical properties of snow, ice, sea ice, and frost. In Zarling, J.P. and S.L. Faussett, eds. Proceedings of the Third International Symposium on Cold Regions Heat Transfer, 11-14 June 1991, Fairbanks, Alaska. Fairbanks, AK, University of Alaska Fairbanks, 187-218.

Yu, Y. and D.W. Lindsay. 2003. Comparison of thin ice distributions derived from RADARSAT Geophysical Processor System and advanced very high resolution radiometer data sets. J. Geophys. Res., 108(C12), 3387. (10.1029/2002JC001319.) 